\title{
Diagnostic accuracy of conventional or age adjusted D-dimer cut-off values in older patients with suspected venous thromboembolism: systematic review and meta-analysis
}

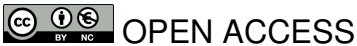

Henrike J Schouten resident in geriatrics ${ }^{12}$, G J Geersing general practitioner ${ }^{1}$, H L Koek geriatrician ${ }^{2}$, Nicolaas P A Zuithoff consultant in applied statistics ${ }^{1}$, Kristel J M Janssen clinical epidemiologist ${ }^{3}$, Renée A Douma resident internal medicine ${ }^{4}$, Johannes J M van Delden professor of medical ethics ${ }^{1}$, Karel G M Moons professor of clinical epidemiology ${ }^{1}$, Johannes B Reitsma associate professor of clinical epidemiology ${ }^{1}$

\footnotetext{
${ }^{1}$ Julius Center for Health Sciences and Primary Care, University Medical Center Utrecht, PO Box 85500, 3508GA Utrecht, Netherlands; ${ }^{2}$ Department of Geriatrics, University Medical Center Utrecht, Utrecht, Netherlands; ${ }^{3}$ Mapi Consultancy, Houten, Netherlands; ${ }^{4}$ Department of Vascular Medicine, Academic Medical Centre, Amsterdam, Netherlands
}

\begin{abstract}
Objective To review the diagnostic accuracy of D-dimer testing in older patients ( $>50$ years) with suspected venous thromboembolism, using conventional or age adjusted D-dimer cut-off values.

Design Systematic review and bivariate random effects meta-analysis. Data sources We searched Medline and Embase for studies published before 21 June 2012 and we contacted the authors of primary studies.

Study selection Primary studies that enrolled older patients with suspected venous thromboembolism in whom D-dimer testing, using both conventional $(500 \mu \mathrm{g} / \mathrm{L})$ and age adjusted (age $\times 10 \mu \mathrm{g} / \mathrm{L})$ cut-off values, and reference testing were performed. For patients with a non-high clinical probability, $2 \times 2$ tables were reconstructed and stratified by age category and applied D-dimer cut-off level.

Results 13 cohorts including 12497 patients with a non-high clinical probability were included in the meta-analysis. The specificity of the conventional cut-off value decreased with increasing age, from $57.6 \%$ (95\% confidence interval $51.4 \%$ to $63.6 \%$ ) in patients aged $51-60$ years to $39.4 \%$ (33.5\% to $45.6 \%$ ) in those aged $61-70,24.5 \%$ (20.0\% to $29.7 \%$ in those aged $71-80$, and $14.7 \%$ (11.3\% to $18.6 \%)$ in those aged $>80$. Age adjusted cut-off values revealed higher specificities over all age categories: $62.3 \%$ (56.2\% to $68.0 \%$ ), $49.5 \%$ (43.2\% to $55.8 \%$ ), $44.2 \%$ (38.0\% to $50.5 \%$ ), and $35.2 \%$ ( $29.4 \%$ to $41.5 \%$ ), respectively. Sensitivities of the age adjusted cut-off remained above $97 \%$ in all age categories.
\end{abstract}

Conclusions The application of age adjusted cut-off values for D-dimer tests substantially increases specificity without modifying sensitivity, thereby improving the clinical utility of D-dimer testing in patients aged 50 or more with a non-high clinical probability.

\section{Introduction}

D-dimer concentrations are highly sensitive for thrombus formation. Hence D-dimer tests are often used to rule-out venous thromboembolism (pulmonary embolism or deep vein thrombosis) in suspected patients with a non-high clinical probability. Patients with a high clinical probability do not require a D-dimer test. In these patients imaging examination is warranted to confirm or refute the diagnosis, irrespective of the D-dimer results (fig $1 \Downarrow$ ). ${ }^{1-3}$ However, D-dimer concentrations increase with age, which leads to a high proportion of older patients with D-dimer concentrations higher than conventional cut-off values $(500 \mu \mathrm{g} / \mathrm{L}){ }^{45}$ This in turn leads to a low specificity (that is, more false positive results) of D-dimer testing in older patients suspected of having venous thromboembolism; the specificity is $49 \%$ to $67 \%$ for patients aged less than 50 years but in older old patients ( $\geq 80$ years) between $0 \%$ and $18 \%$. $^{4-8}$ As imaging is indicated in patients suspected of having venous thromboembolism with a D-dimer concentration above the cut-off value, ${ }^{9}$ a high proportion of older patients with a non-high clinical probability undergo unnecessary diagnostic 
investigations. This can be burdensome, especially in older patients, and the yield of this imaging is relatively low (typically $20 \%$ or less of patients with clinically suspected venous thromboembolism are actually affected). ${ }^{10}$ As a result of a low specificity of D-dimer testing in older patients, some authors dissuade doctors from D-dimer testing in very old patients. ${ }^{4} 12$ Yet this would actually imply referring all suspected older patients for imaging, which is even less desirable.

Others have argued for increasing the D-dimer cut-off value in older patients to improve the specificity and thereby increase the number of patients in whom-based on a D-dimer level below the cut-off value-imaging could be avoided. ${ }^{4}{ }^{13-15}$ An age adjusted D-dimer cut-off value that increases gradually with age especially showed a promising increase in specificity without substantial loss of safety. ${ }^{6}$ This age adjusted cut-off value was defined as age (years) $\times 10 \mu \mathrm{g} / \mathrm{L}$ for patients aged over 50 years (for example, for a patient aged 78 years, the D-dimer concentration would be considered normal below $780 \mu \mathrm{g} / \mathrm{L}$ ). The age adjusted cut-off value was derived from a cohort of secondary care patients with a non-high probability of pulmonary embolism. This cohort was subdivided into 10 year age groups and the optimal cut-off value was selected for each age group - that is, the cut-off value with a sensitivity of $100 \%$ and the highest accompanying specificity. This revealed an increase of the optimal cut-off value of approximately $100 \mu \mathrm{g} / \mathrm{L}$ per decade $(10 \mu \mathrm{g} / \mathrm{L}$ per year). This age adjusted cut-off value was subsequently validated in secondary care patients with suspected pulmonary embolism, ${ }^{16}{ }^{17}$ and in both primary and secondary care cohorts of patients with suspected deep vein thrombosis. ${ }^{18}{ }^{19}$ However, higher cut-off values may also lead to an increased percentage of false negative cases (that is, missed cases of venous thromboembolism), which might make this strategy less safe. ${ }^{20}{ }^{21}$ Since venous thromboembolism has a high short term mortality rate in older patients, doctors do not always get the chance to reconsider a missed diagnosis. ${ }^{22} 23$

Controversy therefore remains on the utility of D-dimer testing (either using the conventional or higher cut-off values) to safely exclude venous thromboembolism in a substantial proportion of older patients. A formal systematic review increases the evidence base on this topic; a meta-analysis can provide more precise estimates of the accuracy of D-dimer testing among clinically relevant subgroups, whereby sources for interstudy heterogeneity can be considered. ${ }^{24}$ We conducted a systematic review and meta-analysis to assess the diagnostic value of D-dimer testing for excluding suspected venous thromboembolism in older patients, with a particular interest in whether increasing the threshold for test positivity using the proposed age adjusted manner is a safe and more efficient strategy than using the conventional cut-off value.

\section{Methods}

\section{Data sources and searches}

On 12 June 2012 we systematically searched Embase and Medline for studies evaluating the diagnostic value of D-dimer tests in diagnosing venous thromboembolism. The search query combined synonyms for "D-dimer" with synonyms for "venous thromboembolism" and "elderly" (see supplementary appendix 1 for the search strategy). ${ }^{25}$ Duplicate articles were manually filtered using the "close match function" of Refworks 2.0.

\section{Study selection}

We included studies if they were original diagnostic studies and comprised a study population of consecutive patients with a clinical suspicion of venous thromboembolism, performed quantitative D-dimer testing using the age adjusted D-dimer cut-off value and the conventional cut-off value, and applied reference testing in all patients according to previously described methods. ${ }^{26}$

No language restrictions were applied. To check cross referencing we used a previously published systematic review. ${ }^{1}$ We excluded studies carried out exclusively in populations with a high risk for thrombosis - defined as perioperative patients or patients with previous thrombosis, cancer, or coagulation disorders. When a study cohort was described by more than one article, we included only the paper best meeting the inclusion criteria. Two reviewers (HJS and NV) independently selected the first batch of articles and a third reviewer (GJG) was consulted by HJS to agree on the final selection and to resolve discrepancies between the first two reviewers.

\section{Data extraction and quality assessment}

We reviewed the included studies in duplicate and extracted the study design, setting, number of patients, prevalence of venous thromboembolism, personal characteristics of the study population, clinical decision rule used to classify patients in risk categories, and reference standard and D-dimer assay applied. Using extracted numbers of true and false positive and negative results according to the reference tests, we reconstructed $2 \times 2$ tables for the patients with a non-high clinical probability and stratified them by predefined age categories ( $\leq 50$ years, $51-60$ years, $61-70$ years, $71-80$ years, and $>80$ years) and by the different $\mathrm{D}$-dimer cut-off values (for the age category $\leq 50$ years the conventional and age adjusted cut-off value are the same). If complete reconstruction of $2 \times 2$ tables using the desired age categories was not possible based on the data presented in the papers, we contacted the authors and requested to reanalyse their data, if needed, according to the predefined age class categories and to complete the cross tables for all age categories and for both the conventional and age adjusted D-dimer cut-off level.

We assessed risk of bias and applicability at study cohort level, using the revised tool for quality assessment of diagnostic accuracy studies (QUADAS-2). This is a validated tool for assessment of methodological quality and applicability of diagnostic accuracy studies. ${ }^{27}$ We appraised both the primary studies describing the included study cohorts and the publications included in this meta-analysis that were based on these cohorts.

\section{Data synthesis and analysis}

From the $2 \times 2$ tables we calculated the prevalence of venous thromboembolism and the D-dimer test sensitivity (the number of patients with venous thromboembolism and a D-dimer level above the tested cut-off value - that is, patients with true positive test results-divided by the total number of patients with venous thromboembolism) and specificity (the number of patients without venous thromboembolism and a D-dimer level below the tested cut-off level-that is, patients with true negative test results - divided by the total number of patients without venous thromboembolism).

To graphically display the sensitivity and specificity measurements at study level we used Review Manager 5 software from the Cochrane collaboration. For the main analyses we stratified the data by age category and D-dimer cut-off value. We used random effects bivariate regression models to meta-analyse the logit transformed sensitivity and specificity of D-dimer to obtain pooled estimates and $95 \%$ confidence intervals of these variables. ${ }^{28}{ }^{29}$ The bivariate approach 
simultaneously models pairs of (logit transformed) sensitivity and specificity from studies, thereby incorporating any correlation that might exist between these measures. The model uses a random effects approach for both sensitivity and specificity to incorporate heterogeneity beyond chance as a result of remaining clinical and methodological differences between studies. We added covariates to the bivariate model to examine whether sensitivity and specificity were different for the following study characteristics: prevalence of venous thromboembolism within each study, the type of applied D-dimer assay, and whether the initial suspicion was deep vein thrombosis or pulmonary embolism in the included studies. We fitted the bivariate random effects models using the NLMIXED (non-linear mixed effect) procedure of SAS version 9.2 (SAS Institute, Cary, NC, USA).

For each age category and D-dimer cut-off level we constructed hypothetical classification tables including 1000 hypothetical patients per table. We calculated the total number of venous thromboembolism cases by multiplying 1000 with the estimated median prevalence of venous thromboembolism within the particular age category based on the studies included in this meta-analysis. We calculated the number of patients with true positive test results by multiplying the total number of hypothetical venous thromboembolism cases with the estimated sensitivity of the D-dimer test in the particular age category (or with the lower or upper $95 \%$ confidence interval border of the estimated sensitivity to extract a measure of uncertainty). To obtain the number of patients with true negative test results we multiplied the total number of hypothetical non-cases by the estimated specificity (or with the lower or upper limits of the $95 \%$ confidence interval of this estimate). To examine the influence of the prevalence on these numbers, we repeated these analyses using the minimum and maximum prevalence of venous thromboembolism within each age group based on this meta-analysis. These analyses were performed in Microsoft Office Excel version 2010.

\section{Results}

\section{Selection, characteristics, and quality of studies}

Our search yielded 2696 unique publications (see flowchart in supplementary appendix 2). After we had screened the titles and abstracts, 307 publications were selected for full text review. Of these publications, 302 were excluded, mainly because they did not concern consecutive patients, applied no (quantitative) D-dimer test, or did not apply age adjusted D-dimer cut-off levels. Finally, five publications were included concerning a total of 22608 patients of whom 12630 had a non-high clinical probability of venous thromboembolism. ${ }^{6}{ }^{16-19}$ All these publications concerned retrospective analyses on one or more cohorts of patients with suspected venous thromboembolism. One publication ${ }^{19}$ separately analysed and presented five different cohorts (Tan et al, unpublished), ${ }^{30-33}$; two

publications ${ }^{6}{ }^{16}$ separately analysed and presented three different cohorts $^{34-39}$ and the other two publications concerned one cohort each. ${ }^{17}{ }^{18}$ Hence the five included publications concerned a total of 13 different study cohorts, which we considered as separate cohorts in this meta-analysis. All authors granted our requests to reanalyse their data and provided $2 \times 2$ tables for each predefined age category and both D-dimer cut-off levels.

Table $1 \Downarrow$ summarises the characteristics of the included study cohorts. Seven cohorts concerned patients with suspected pulmonary embolism ${ }^{17}{ }^{34-39}$ and the other six concerned patients with suspected deep vein thrombosis (Tan et al, unpublished). ${ }^{180-33}$ All studies analysed and presented only patients with non-high clinical probability scores on clinical decision rules as this is the indicated population for the application of D-dimer tests. ${ }^{39}$ To select these patients with a non-high clinical probability, either a revised Geneva score ${ }^{40}$ of $\leq 10$ or a Wells score ${ }^{41}$ of $\leq 4$ was applied in the pulmonary embolism cohorts; and for the deep vein thrombosis cohorts, a Wells score ${ }^{9}$ of either $\leq 2$ or $\leq 1$ was applied. In one study, ${ }^{31}$ a clinical probability of $<80 \%$ of deep vein thrombosis as estimated by the treating doctor-instead of a formal clinical decision rule-was used to select the patients with a non-high clinical probability.

One study was performed in primary care, ${ }^{18}$ whereas all other cohorts concerned patients presenting at emergency departments or in outpatients clinics; in two studies, inpatients were also included. ${ }^{1735}$

Overall, the quality of the included study cohorts was good (see the results of QUADAS-2 in supplementary appendix 3). All but one cohort ${ }^{42}$ included prospectively collected data of consecutive patients with suspected venous thromboembolism. However, in 12 of the 13 study cohorts, three month event free follow-up (no signs or symptoms of recurrence) instead of imaging investigation was used as the reference test in patients with a negative D-dimer result and a non-high clinical probability, so not all patients underwent the same sequence of reference tests in these studies. Hence differential verification could have introduced bias. Furthermore, there were concerns about the applicability of the studies, as unstratified data for different applied D-dimer assays (enzyme linked fluorescent assays as well as quantitative latex assays) within one study cohort was presented for six of the 13 study cohorts.

\section{Prevalence of venous thromboembolism and effect of age on specificity and sensitivity of D-dimer testing with a conventional cut-off value}

The median prevalence of venous thromboembolism in patients not at high risk ranged from $12.3 \%$ in patients aged less than 50 years, to $21.5 \%$ in patients aged $71-80$ (table $2 \Downarrow$ ). The pooled specificity of D-dimer testing decreased substantially with increasing age from $66.8 \%$ (95\% confidence interval $61.3 \%$ to $72.0 \%)$ in patients aged less than 50 years to $14.7 \%$ (11.3\% to $18.6 \%$ ) in patients aged more than 80 years when the conventional cut-off value was applied (table 2 ). The pooled sensitivity hardly differed between the age groups.

\section{Performance of age adjusted D-dimer cut-off values}

The use of the age adjusted D-dimer cut-off value (agex $10 \mu \mathrm{g} / \mathrm{L}$ in patients aged $>50$ years) still showed a decrease in specificity with increasing age, which was $35.2 \%$ (29.4\% to $41.5 \%)$ in patients aged more than 80 years, but noticeably less pronounced compared with the application of the conventional cut-off value. The specificity of D-dimer testing by application of the age adjusted D-dimer cut-off value instead of the conventional cut-off value was higher in all age categories and was more than doubled in patients aged more than 80 years (table 2 ).

The use of age adjusted cut-off values instead of the conventional cut-off value was at the expense of a decrease in sensitivity (albeit small and not statistically significant), which stayed above $97 \%$ for both cut-off levels in all age categories. 


\section{Covariates}

The forest plot in supplementary appendix 4 depicts the sensitivity and specificity of D-dimer testing stratified by cohort, age group, and D-dimer cut-off level. We analysed the effect of covariates (the venous thromboembolism prevalence in each total cohort, applied D-dimer assays, and whether the patients were initially suspected of having pulmonary embolism or deep vein thrombosis) on the D-dimer sensitivity and specificity (table $3 \Downarrow$ ). We found no association between the sensitivity and specificity of D-dimer testing and the prevalence of venous thromboembolism in the study populations or whether patients were suspected of having either pulmonary embolism or deep vein thrombosis.

D-dimer testing revealed a higher sensitivity and a trend towards lower specificity in the three cohorts in which only enzyme linked fluorescent assays were applied, compared with the cohorts in which quantitative latex assays were also used. Besides, the enzyme linked fluorescent assays showed less decrease in sensitivity by application of the age adjusted cut-off value instead of the conventional cut-off.

\section{Hypothetical cohort}

Based on hypothetical cohorts of 1000 patients for each age category, we calculated the numbers of extra patients in whom imaging examination would, correctly or wrongly, be avoided by using the age adjusted instead of the conventional D-dimer cut-off value (table $4 \Downarrow$ ). This would result in a correct exclusion of venous thromboembolism in 40 (95\% confidence interval 38 to 41 ), 85 ( 81 to 86 ), 155 (141 to 164 ), and 175 (153 to 194 ) extra patients at the expense of 1 ( 0 to 4$)$ extra missed cases for those aged 51-60 years, 2 (2 to 5) for those aged 61-70 years, 3 ( 2 to 4 ), for those aged 71-80 years, and 4 (2 to 6 ) for those aged more than 80 years. D-dimer testing would rule out venous thromboembolism in 124 per 1000 non-high risk patients aged more than 80 years if the conventional cut-off value would be applied, whereas the application of the age adjusted D-dimer cut-off value results in exclusion of venous thromboembolism in 303 per 1000 of these patients. The positive predictive value was $21.2 \%$ (95\% confidence interval $19.1 \%$ to $23.2 \%$ ) in patients aged more than 80 years and $29.1 \%$ (25.3\% to $33.1 \%$ ) in patients aged 50 years or less. To examine the influence of the prevalence on this figure we also compared these numbers for the lowest and highest prevalence of venous thromboembolism of the non-high risk patients within each age category of the studies in this meta-analysis (fig $2 \Downarrow$ ). The relative merit of application of the age adjusted cut-off value instead of the conventional cut-off value was higher in the case of a low prevalence (44-194 correct $v$ 0-2 falsely excluded cases) compared with a high prevalence (31-150 correctly $v$ 2-7 falsely excluded cases) (see fig 2 and supplementary appendix 5).

\section{Discussion}

We performed a systematic review and meta-analysis on the diagnostic value of $\mathrm{D}$-dimer testing to exclude venous thromboembolism in older patients aged 50 or more years. Generally, in combination with a non-high clinical probability, D-dimer testing is used as a rule-out test in patients with suspected venous thromboembolism. Using such a rule-out approach, unnecessary burdensome and more costly imaging can be avoided in about 1 in 3 patients. ${ }^{1}{ }^{30}{ }^{33-35}$ However, this proportion of patients in whom imaging can be safely withheld by using D-dimer testing seemed to be low (around 10\%) in the eldest patients ( $>80$ years). ${ }^{48} 12$ This has led to controversy over the diagnostic value of D-dimer testing in older old patients
( $>80$ years) with clinically suspected venous thromboembolism. In particular old, fragile patients, who would benefit if an unnecessary referral to a radiology department could be safely avoided. ${ }^{43}$ In fact, this was the main reason for the development of age adjusted cut-off values for D-dimer testing ${ }^{6}$ and thereby the reason for this aggregated meta-analysis.

Indeed we found a sharp decrease in the specificity of D-dimer testing to rule out venous thromboembolism in older patients with a non-high clinical probability using the conventional D-dimer cut-off value, although the sensitivities of D-dimer testing were high across all age categories. The proportion of patients with a non-high clinical probability in whom D-dimer testing could exclude venous thromboembolism was only $12.4 \%$ in those aged more than 80 years. This finding underlines the arguments of several authors that D-dimer testing in this conventional way is of limited value in the eldest patients. ${ }^{4} 812$ Yet the application of the age adjusted D-dimer cut-off value ${ }^{6}$ would result in the exclusion of venous thromboembolism in almost 1 out of $3(30.3 \%)$ of the eldest patients ( $>80$ years), while the sensitivity stayed above $97 \%$ in all age categories. This would lead to one identified and treated patient for every five patients undergoing imaging examinations in the eldest patients, or in other words a positive predictive value of $21.1 \%$. This positive predictive value of $\mathrm{D}$-dimer testing in the eldest patients is almost comparable to the positive predictive value of $29.2 \%$ in the youngest patients $(<50$ years, cut-off value of $500 \mu \mathrm{g} / \mathrm{L}$ ). The small number of missed cases from applying the age adjusted cut-off value instead of the conventional cut-off ( 1 to 4 per 1000 ) is largely outnumbered by the large number of patients in whom imaging would be avoided (303 to 540 per 1000). Moreover, this number of missed cases from using the age adjusted cut-off value is comparable to the failure rate in the youngest age category ( $\leq 50$ years) in whom 3 per 1000 patients would be missed if $\mathrm{D}$-dimer testing using conventional cut-off levels was used. Even in case of a high prevalence of venous thromboembolism (when the relative merit of application of the age adjusted cut-off value is lowest) the additional number of patients missed ( 2 to 7 per 1000) would be outweighed by the number of avoided unnecessary imaging examinations (31 to 150 per 1000).

Currently, broadly available imaging techniques for the detection of venous thromboembolism have replaced burdensome and time consuming techniques bringing about high radiation exposure (repeated two point compression ultrasonography replaced venography for the detection of deep vein thrombosis, and contrast enhanced computed tomography of the pulmonary arteries replaced pulmonary angiography for pulmonary embolism). ${ }^{35}{ }^{44}$ Still, the burden and risks of imaging, such as attending a hospital, extension of hospital stay, waiting at a radiology department, are of particular concern for old patients. ${ }^{43}$ Moreover, contrast enhanced computed tomography of the pulmonary arteries is associated with a $14 \%$ risk of nephropathy, which might be even higher in older patients in whom renal impairment is more common. ${ }^{45}$ Therefore it would (notably for older patients) be beneficial to safely withhold imaging investigations based on negative D-dimer test results.

\section{Strengths and limitations of this review}

This is the first systematic review and meta-analysis on the diagnostic utility of D-dimer testing in older patients. We were able to include 13 large cohorts involving over 12000 patients wherein both the conventional adjusted and the age adjusted cut-off values were studied in different age categories. However, the included publications were from only three research groups. Our search yielded another 107 publications in which the 
diagnostic accuracy of quantitative D-dimer testing had been examined in consecutive patients, but as this was not done in an age adjusted manner these publications were not included in our meta-analysis. Yet given the robustness, precision, and consistency of our results over the 13 included cohorts, we expect that the addition of more studies to the meta-analysis would not have changed our inferences. Moreover, funnel plots of estimates of the effect size (differences in logit specificities within studies as a result of the application of the different cut-off levels) against the study size, gave (although based on a small number of studies) no indication for publication bias (analysis not presented).

Other strategies to adjust the D-dimer cut-off value to exclude venous thromboembolism in older patients have been suggested-for example, a fixed cut-off of $750 \mu \mathrm{g} / \mathrm{L}$ in all patients aged over 60 or 70 years. ${ }^{14214647}$ Owing to the heterogeneity of the applied D-dimer assays, methodology, and categorization of age (for example, $>60$ or $>70$ years instead of 61-70 years, $71-80$ years, and $>80$ years), we were unable to provide pooled estimates of the studies that analysed alternative D-dimer cut-off levels. This hampered the comparison of the different adjusted D-dimer cut-off values.

We also found some heterogeneity in the sensitivity and specificity of D-dimer tests among the studies, partly explained by the application of different assays. Our covariate analysis suggests that the application of age adjusted instead of conventional cut-off values was most favourable in the cohorts in which enzyme linked fluorescent assays were only applied, as the high sensitivity remained constant in these cohorts. These findings are consistent with previous studies: enzyme linked fluorescent assays turned out to have a higher sensitivity at the expense of a lower specificity compared with second generation latex assays. ${ }^{248}$ However, as a result of between study variation of covariates and their potential multicollinearity (linear relation between explaining variables), we are unable to draw firm conclusions on the differences between various D-dimer assays based on our current meta-analysis.

Another limitation might be that we included studies both with populations suspected of having pulmonary embolism and with populations suspected of having deep vein thrombosis, and primary as well as secondary care patients, which might have introduced some extra between study variation. Furthermore, there was a variation in the prevalence of venous

thromboembolism in the included cohorts, ranging from $5.1 \%$ to $39 \%$. However, although previous studies revealed an association between the prevalence of venous thromboembolism and the diagnostic accuracy of D-dimer testing, ${ }^{49}$ our covariate analysis did not show such an association. Moreover, there was a fair similarity of study design and patient selection over the included cohorts; in all studies only patients with a non-high clinical probability were selected. Therefore we assumed that the conditions for pooling were met.

Finally, the reference standards used to diagnose or exclude venous thromboembolism differed between the included studies. In all but one study ${ }^{18}$ differential verification was of concern; in these studies venous thromboembolism was excluded without confirmation by imaging in patients with a negative $\mathrm{D}$-dimer test result and without recurrence of symptoms during follow-up. Hence the false negative cases from using the conventional cut-off value were patients presenting with worsening or recurrence of their symptoms within 45 days or three months, leading to further examinations and the detection of venous thromboembolism. Although this is common practice, this could have introduced small overestimations of the diagnostic accuracy of the D-dimer test, as small thrombi may have been missed in these patients.

\section{Conclusions and implications for further research}

D-dimer testing has limited utility in older patients when the conventional cut-off value is applied. The application of the age adjusted cut-off value combined with a non-high clinical probability greatly increases the utility of a $\mathrm{D}$-dimer test for the exclusion of venous thromboembolism in older patients, while hardly affecting the sensitivity. D-dimer levels below the age adjusted cut-off value correctly avoided imaging examinations in $30 \%$ to $54 \%$ of older patients with a non-high probability. This meta-analysis shows the robustness of our findings for patients with suspected deep vein thrombosis or pulmonary embolism, as well as for different age groups, D-dimer assays, and prevalence of venous thromboembolism.

Given that the age adjusted cut-off level could be easily implemented in routine laboratory practice it may have an immediate impact in clinical practice and serve the needs of older patients with a non-high clinical probability of venous thromboembolism by sparing a substantial proportion the burden of imaging investigations. Our results are not, however, applicable to patients with a high clinical probability of venous thromboembolism as additional imaging examination is warranted in these patients, irrespective of the D-dimer test results. Furthermore, since this strategy has only been confirmed in retrospective analyses, it could be argued that a formal cost effectiveness modeling study ${ }^{50}$ or even a prospective impact study $^{5253}$ is needed to further confirm the cost effectiveness and ease of use and acceptability of this diagnostic strategy in daily patient care before its implementation in clinical practice.

We thank Nienke A F Verheijden for double checking our search and data extraction; Bianca Kramer for her help in the design of the search syntax; and Andrea Penaloza, Josien van Es, Gregoire Le Gal, Roger Schutgens, Cristina Legnani, Shanon Bates, Menno Huisman, and Melanie Tan for providing additional data.

Contributors: HJS, GJG, and JBR participated in the study concept and design, interpretation of data, and drafting of the manuscript. HJS, GJG, and NV performed the search and data extraction. RAD acquired additional data and critically revised the manuscript. HLK, KJMJ, and NPAZ critically revised the manuscript. JBR and NPAZ participated in analysis of the data. JBR, KGMM, and JJMD provided critical revision of the manuscript and study supervision. All authors had full access to all data in the study and take responsibility for the integrity of the data and the accuracy of the data analysis. All authors participated in the revision and final approval of the manuscript.

Funding: This study was supported by the Netherlands Organization for Scientific Research (ZonMw project No 9120-8004, 918-10-615, and 17088-2502). The funder had no role in the study design, data collection and analysis, decision to publish, or preparation of the manuscript.

Competing interests: All authors have completed the ICMJE uniform disclosure form at www.icmje.org/coi_disclosure.pdf (available on request from the corresponding author) and declare: all authors had financial support from the Netherlands Organization for Scientific Research (ZonMw project No 17088-2502, 917-46-360, and 945-04-009) for the submitted work; no financial relationships with any organisations that might have an interest in the submitted work in the previous three years; no other relationships or activities that could appear to have influenced the submitted work.

Ethical approval: Not required.

Data sharing: No additional data available. 


\section{What is already known on this topic}

A negative $\mathrm{D}$-dimer test can rule out venous thromboembolism in patients with a non-high clinical probability

Since D-dimer levels increase with age, the proportion of false positive D-dimer test results for venous thromboembolism using conventional cut-off values $(500 \mu \mathrm{g} / \mathrm{L})$ increases in older patients and the specificity decreases

Age adjusted D-dimer cut-off values (age $\times 10 \mu g / L$ ) have therefore been introduced

\section{What this study adds}

This systematic review and meta-analysis established a poor specificity (around 15\%) of D-dimer testing with the conventional cut-off value in the eldest patients ( $>80$ years)

The application of the age adjusted cut-off value increased the specificity of the D-dimer test to $35 \%$ in the eldest patients, while hardly affecting the sensitivity

Use of age adjusted D-dimer cut-off values would result in imaging examinations being correctly avoided in $30-54 \%$ of older patients with a non-high clinical probability of venous thromboembolism

1 Stein PD, Hull RD, Patel KC, Olson RE, Ghali WA, Brant R, et al. D-dimer for the exclusion of acute venous thrombosis and pulmonary embolism: a systematic review. Ann Intern Med 2004; 140:589-602.

2 Di Nisio M, Squizzato A, Rutjes AW, Buller HR, Zwinderman AH, Bossuyt PM. Diagnostic accuracy of D-dimer test for exclusion of venous thromboembolism: a systematic review. J Thromb Haemost 2007:5:296-304.

3 Gibson NS, Sohne M, Gerdes VE, Nijkeuter M, Buller HR. The importance of clinical probability assessment in interpreting a normal d-dimer in patients with suspected pulmonary embolism. Chest 2008;134:789-93.

4 Harper PL, Theakston E, Ahmed J, Ockelford P. D-dimer concentration increases with age reducing the clinical value of the $\mathrm{D}$-dimer assay in the elderly. Intern $\mathrm{Med} J$ 2007;37:607-13.

5 Righini M, Le Gal G, Perrier A, Bounameaux H. The challenge of diagnosing pulmonary embolism in elderly patients: influence of age on commonly used diagnostic tests and strategies. J Am Geriatr Soc 2005;53:1039-45.

6 Douma RA, Le Gal G, Sohne M, Righini M, Kamphuisen PW, Perrier A, et al. Potential of an age adjusted D-dimer cut-off value to improve the exclusion of pulmonary embolism in older patients: a retrospective analysis of three large cohorts. BMJ 2010;340:c1475.

7 Schutgens RE, Haas FJ, Biesma DH. Reduced efficacy of clinical probability score and D-dimer assay in elderly subjects suspected of having deep vein thrombosis. Br J Haematol 2005;129:653-7.

8 Barro C, Bosson JL, Pernod G, Carpentier PH, Polack B. Plasma D-dimer testing improves the management of thromboembolic disease in hospitalized patients. Thromb Res 1999;95:263-9.

9 Wells PS. Integrated strategies for the diagnosis of venous thromboembolism. J Thromb Haemost 2007:5( Suppl 1):41-50.

10 Bounameaux $\mathrm{H}$. Contemporary management of pulmonary embolism: the answers to ten questions. J Intern Med 2010;268:218-31.

11 Penaloza A, Kline J, Verschuren F, Courtney DM, Zech F, Derrien B, et al. European and American suspected and confirmed pulmonary embolism populations: comparison and analysis. J Thromb Haemost 2012;10:375-81.

12 Righini M, Nendaz M, Le Gal G, Bounameaux H, Perrier A. Influence of age on the cost-effectiveness of diagnostic strategies for suspected pulmonary embolism. J Thromb Haemost 2007;5:1869-77.

13 Righini M, Goehring C, Bounameaux $\mathrm{H}$, Perrier A. Effects of age on the performance of common diagnostic tests for pulmonary embolism. Am J Med 2000;109:357-61.

14 Haas FJ, Schutgens RE, Biesma DH. An age-adapted approach for the use of D-dimers in the exclusion of deep venous thrombosis. Am J Hematol 2009;84:488-91.

15 Aguilar C, Martinez A, Martinez A, Del RC, Vazquez M. Diagnosis of deep venous thrombosis in the elderly: a higher D-dimer cut-off value is better? Haematologica 2001;86:E28.

16 Penaloza A, Roy PM, Kline J, Verschuren F, Le Gal G, Quentin-Georget S, et al. Performance of age-adjusted D-dimer cut-off to rule out pulmonary embolism. J Thromb Haemost 2012;10:1291-6.

17 Van Es J, Mos I, Douma R, Erkens P, Durian M, Nizet T, et al. The combination of four different clinical decision rules and an age-adjusted $\mathrm{D}$-dimer cut-off increases the number of patients in whom acute pulmonary embolism can safely be excluded. Thromb Haemost 2012;107:167-71

18 Schouten HJ, Koek HL, Oudega R, Geersing GJ, Janssen KJ, van Delden JJ et al. Validation of two age dependent $\mathrm{D}$-dimer cut-off values for exclusion of deep vein thrombosis in suspected elderly patients in primary care: retrospective, cross sectional, diagnostic analysis. BMJ 2012;344:e2985.

19 Douma RA, Tan M, Schutgens R, Bates SM, Perrier A, Legnani C, et al. Age-dependent $D$-dimer cut-off value increases the number of older patients in whom deep vein thrombosis can be safely excluded. Haematologica 2012:97:1507-13.

20 Righini M, Aujesky D, Roy PM, Cornuz J, de Moerloose P, Bounameaux $\mathrm{H}$, et al. Clinical usefulness of $\mathrm{D}$-dimer depending on clinical probability and cutoff value in outpatients with suspected pulmonary embolism. Arch Intern Med 2004;164:2483-7.

21 Righini M, de Moerloose P, Reber G, Perrier A, Bounameaux H. Should the D-dimer cut-off value be increased in elderly patients suspected of pulmonary embolism? Thromb Haemost 2001;85:744.

22 White RH. The epidemiology of venous thromboembolism. Circulation 2003;107(23 Suppl 1):14-8.

23 Anderson FA Jr, Wheeler HB, Goldberg RJ, Hosmer DW, Patwardhan NA, Jovanovic B et al. A population-based perspective of the hospital incidence and case-fatality rates of deep vein thrombosis and pulmonary embolism. The Worcester DVT Study. Arch Intern Med 1991;151:933-8.

24 Reitsma JB, Moons KG, Bossuyt PM, Linnet K. Systematic reviews of studies quantifying the accuracy of diagnostic tests and markers. Clin Chem 2012;58:1534-45.

25 Van de Glind EM, van Munster BC, Spijker R, Scholten RJ, Hooft L. Search filters to identify geriatric medicine in Medline. J Am Med Inform Assoc 2012;19:468-72.

26 Geersing GJ, Janssen KJ, Oudega R, Bax L, Hoes AW, Reitsma JB, et al. Excluding venous thromboembolism using point of care D-dimer tests in outpatients: a diagnostic meta-analysis. BMJ 2009;339:b2990.
27 Whiting PF, Rutjes AW, Westwood ME, Mallett S, Deeks JJ, Reitsma JB, et al. QUADAS-2: a revised tool for the quality assessment of diagnostic accuracy studies. Ann Intern Med 2011;155:529-36

28 Reitsma JB, Glas AS, Rutjes AW, Scholten RJ, Bossuyt PM, Zwinderman AH. Bivariate analysis of sensitivity and specificity produces informative summary measures in diagnostic reviews. J Clin Epidemiol 2005:58:982-90.

29 Hamza TH, Reitsma JB, Stijnen T. Meta-analysis of diagnostic studies: a comparison of random intercept, normal-normal, and binomial-normal bivariate summary ROC approaches. Med Decis Making 2008;28:639-49.

30 Schutgens RE, Ackermark P, Haas FJ, Nieuwenhuis HK, Peltenburg HG, Pijlman AH, et al. Combination of a normal D-dimer concentration and a non-high pretest clinical probability score is a safe strategy to exclude deep venous thrombosis. Circulation 2003:107:593-7.

31 Perrier A, Desmarais S, Miron MJ, de Moerloose P, Lepage R, Slosman D, et al. Non-invasive diagnosis of venous thromboembolism in outpatients. Lancet 1999;353:190-5.

32 Legnani C, Cini M, Scarvelis D, Toulon P, Wu JR, Palareti G. Multicenter evaluation of a new quantitative highly sensitive D-dimer assay, the Hemosil D-dimer HS 500, in patients with clinically suspected venous thromboembolism. Thromb Res 2010;125:398-401.

33 Bates SM, Kearon C, Crowther M, Linkins L, O'Donnell M, Douketis J, et al. A diagnostic strategy involving a quantitative latex D-dimer assay reliably excludes deep venous thrombosis. Ann Intern Med 2003;138:787-94.

34 Perrier A, Roy PM, Sanchez O, Le Gal G, Meyer G, Gourdier AL, et al. Multidetector-row computed tomography in suspected pulmonary embolism. N Engl J Med 2005;352:1760-8.

35 Van Belle A, Buller HR, Huisman MV, Huisman PM, Kaasjager K, Kamphuisen PW, et al. Effectiveness of managing suspected pulmonary embolism using an algorithm combining clinical probability, D-dimer testing, and computed tomography. JAMA 2006;295:172-9.

36 Righini M, Le Gal G, Aujesky D, Roy PM, Sanchez O, Verschuren F, et al. Diagnosis of pulmonary embolism by multidetector $\mathrm{CT}$ alone or combined with venous ultrasonography of the leg: a randomised non-inferiority trial. Lancet 2008;371:1343-52.

37 Roy PM, Durieux P, Gillaizeau F, Legall C, Armand-Perroux A, Martino L, et al. A computerized handheld decision-support system to improve pulmonary embolism diagnosis: a randomized trial. Ann Intern Med 2009;151:677-86.

38 Roy PM, Meyer G, Vielle B, Le Gall C, Verschuren F, Carpentier F, et al. Appropriateness of diagnostic management and outcomes of suspected pulmonary embolism. Ann Intern Med 2006:144:157-64.

39 Kline JA, Courtney DM, Kabrhel C, Moore CL, Smithline HA, Plewa MC, et al. Prospective multicenter evaluation of the pulmonary embolism rule-out criteria. $J$ Thromb Haemost 2008:6:772-80.

40 Le Gal G, Righini M, Roy PM, Sanchez O, Aujesky D, Bounameaux H, et al. Prediction of pulmonary embolism in the emergency department: the revised Geneva score. Ann Intern Med 2006;144:165-71.

41 Wells PS, Anderson DR, Rodger M, Ginsberg JS, Kearon C, Gent M, et al. Derivation of a simple clinical model to categorize patients probability of pulmonary embolism: increasing the models utility with the SimpliRED D-dimer. Thromb Haemost 2000;83:416-20.

42 Kline JA, Courtney DM, Kabrhel C, Moore CL, Smithline HA, Plewa MC, et al. Prospective multicenter evaluation of the pulmonary embolism rule-out criteria. $J$ Thromb Haemost 2008;6:772-80.

43 Gill TM, Gahbauer EA, Han L, Allore HG. The relationship between intervening hospitalizations and transitions between frailty states. J Gerontol A Biol Sci Med Sci 2011;66:1238-43.

44 Bernardi E, Camporese G, Buller HR, Siragusa S, Imberti D, Berchio A, et al. Serial 2-point ultrasonography plus D-dimer vs whole-leg color-coded Doppler ultrasonography for diagnosing suspected symptomatic deep vein thrombosis: a randomized controlled trial. JAMA 2008:300:1653-9.

45 Mitchell AM, Jones AE, Tumlin JA, Kline JA. Prospective study of the incidence of contrast-induced nephropathy among patients evaluated for pulmonary embolism by contrast-enhanced computed tomography. Acad Emerg Med 2012;19:618-25.

46 Tardy B, Tardy-Poncet B, Viallon A, Lafond P, Page Y, Venet C, et al. Evaluation of D-dimer ELISA test in elderly patients with suspected pulmonary embolism. Thromb Haemost 1998;79:38-41.

47 Le Blanche AF, Siguret V, Settegrana C, Bohus S, Le Masne de CE, Andreux JP, et al. Ruling out acute deep vein thrombosis by ELISA plasma D-dimer assay versus ultrasound in inpatients more than 70 years old. Angiology 1999;50:873-82.

48 Heim SW, Schectman JM, Siadaty MS, Philbrick JT. D-dimer testing for deep venous thrombosis: a metaanalysis. Clin Chem 2004;50:1136-47.

49 Lucassen W, Geersing GJ, Erkens PM, Reitsma JB, Moons KG, Buller H, et al. Clinical decision rules for excluding pulmonary embolism: a meta-analysis. Ann Intern Med 2011;155:448-60.

50 Schaafsma JD, van der GY, Rinkel GJ, Buskens E. Decision analysis to complete diagnostic research by closing the gap between test characteristics and cost-effectiveness. J Clin Epidemiol 2009;62:1248-52. 
51 Koffijberg $\mathrm{H}$, van Zaane B, Moons KG. From accuracy to patient outcome and cost-effectiveness evaluations of diagnostic tests and biomarkers: an exemplary modelling study. BMC Med Res Methodol 2013;13:12.

52 Moons KG, Altman DG, Vergouwe $Y$, Royston P. Prognosis and prognostic research: application and impact of prognostic models in clinical practice. BMJ 2009;338:b606.

53 Reilly BM, Evans AT. Translating clinical research into clinical practice: impact of using prediction rules to make decisions. Ann Intern Med 2006;144:201-9.

54 Wells PS, Ginsberg JS, Anderson DR, Kearon C, Gent M, Turpie AG, et al. Use of a clinical model for safe management of patients with suspected pulmonary embolism. Ann Intern Med 1998;129:997-1005.

55 Douma RA, Mos IC, Erkens PM, Nizet TA, Durian MF, Hovens MM, et al. Performance of 4 clinical decision rules in the diagnostic management of acute pulmonary embolism: a prospective cohort study. Ann Intern Med 2011;154:709-18.

56 Oudega R, Moons KG, Hoes AW. Ruling out deep venous thrombosis in primary care. A simple diagnostic algorithm including D-dimer testing. Thromb Haemost 2005;94:200-5.
57 Wells PS, Anderson DR, Rodger M, Stiell I, Dreyer JF, Barnes D, et al. Excluding pulmonary embolism at the bedside without diagnostic imaging: management of patients with suspected pulmonary embolism presenting to the emergency department by using a simple clinical model and d-dimer. Ann Intern Med 2001;135:98-107.

\section{Accepted: 25 March 2013}

\section{Cite this as: BMJ 2013;346:f2492}

This is an Open Access article distributed in accordance with the Creative Commons Attribution Non Commercial (CC BY-NC 3.0) license, which permits others to distribute, remix, adapt, build upon this work non-commercially, and license their derivative works on different terms, provided the original work is properly cited and the use is non-commercial. See: http://creativecommons.org/licenses/by-nc/3.0/. 


\section{Tables}

Table 1| Characteristics of included study cohorts. Data were sorted according to primary suspicion of pulmonary embolism (PE) or deep vein thrombosis (DVT) and setting. All studies used D-dimer cut-off value of $500 \mathrm{ug} / \mathrm{L}$ and age $\times 10 \mu \mathrm{g} / \mathrm{L}$

\begin{tabular}{|c|c|c|c|c|c|c|c|c|}
\hline Reference $^{*}$ & $\begin{array}{l}\text { PE or } \\
\text { DVT }\end{array}$ & $\begin{array}{c}\text { No of } \\
\text { patients } \\
(\% \text { male })\end{array}$ & $\begin{array}{c}\text { Mean } \\
\text { age (SD) }\end{array}$ & $\begin{array}{l}\text { Prevalence } \\
\text { of VTE (\%) }\end{array}$ & Setting & Reference test to rule out VTE & D-dimer assay $\dagger$ & $\begin{array}{l}\text { CDR used } \\
\text { (cut-off) }\end{array}$ \\
\hline $\begin{array}{l}\text { Douma 2010, } \\
\text { derivation set }{ }^{634}\end{array}$ & PE & $1721(41)$ & $61(19)$ & 24 & $\begin{array}{l}\text { Hospital; outpatients } \\
\text { presenting in emergency } \\
\text { department or outpatient } \\
\text { clinics }\end{array}$ & $\begin{array}{l}\text { ((a) D-dimer }<500 \mu \mathrm{g} / \mathrm{L} \text {; or }(\mathrm{b}) \\
\text { negative results from CUS and from } \\
\mathrm{HCT} \text { in patients with non-high CDR; } \\
\text { or (c) normal VQ scan or normal } \\
\text { pulmonary angiogram) and ( } 3 \text { month } \\
\text { event free follow-up) }\end{array}$ & ELFA & Wells $^{54}(\leq 4)$ \\
\hline $\begin{array}{l}\text { Douma 2010, } \\
\text { validation set } 2^{6} \\
\text { 36 }\end{array}$ & PE & $1819(49)$ & $59(19)$ & 21 & $\begin{array}{l}\text { Hospital; outpatients } \\
\text { presenting in emergency } \\
\text { department or outpatient } \\
\text { clinics }\end{array}$ & $\begin{array}{l}\text { ((a) Non-high CDR and D-dimer }<500 \\
\mu g / L ; \text { or (b) negative HCT) and ( } 3 \\
\text { month event free follow-up) }\end{array}$ & ELFA & $\begin{array}{l}\text { Revised } \\
\text { Geneva } \\
\text { score }^{40}(\leq 10)\end{array}$ \\
\hline $\begin{array}{l}\text { Penaloza 2012, } \\
\text { French cohort } \\
\text { 38 }\end{array}$ & PE & 1529 (39) & Not given & 28 & $\begin{array}{l}\text { Hospital; outpatients } \\
\text { presenting in emergency } \\
\text { department or outpatient } \\
\text { clinics }\end{array}$ & $\begin{array}{l}\text { ((a) D-dimer <500 } \mu \mathrm{g} / \mathrm{L} \text {; or (b) normal } \\
\text { pulmonary angiogram; or (c) negative } \\
\text { VQ scan; or (d) negative HCT; or (e) } \\
\text { low CDR and non-diagnostic VQ or } \\
\text { HCT and negative CUS) and ( } 3 \text { month } \\
\text { event free follow-up) }\end{array}$ & $\begin{array}{l}\text { ELFA or } \\
\text { quantitative latex } \\
\text { agglutination } \\
\text { assay }\end{array}$ & $\begin{array}{l}\text { Revised } \\
\text { Geneva } \\
\text { score }^{40}(\leq 10)\end{array}$ \\
\hline $\begin{array}{l}\text { Penaloza 2012, } \\
\text { European } \\
\text { cohort }^{1637}\end{array}$ & PE & $1645(42)$ & 59 & 18 & $\begin{array}{l}\text { Hospital; outpatients } \\
\text { presenting in emergency } \\
\text { department or outpatient } \\
\text { clinics }\end{array}$ & $\begin{array}{l}\text { (a) Non-high CDR and D-dimer ELISA } \\
<500 \mu \mathrm{g} / \mathrm{L} \text {; or (b) non-high CDR and } \\
\text { negative moderate sensitivity D-dimer } \\
\text { test; or (c) low CDR and low } \\
\text { probability VQ scan or negative } \\
\text { computed tomography angiography; } \\
\text { or (d) negative multidetector HCT }\end{array}$ & $\begin{array}{l}\text { ELFA or } \\
\text { quantitative latex } \\
\text { agglutination } \\
\text { assay }\end{array}$ & $\begin{array}{l}\text { Revised } \\
\text { Geneva } \\
\text { score }^{40}(\leq 10)\end{array}$ \\
\hline $\begin{array}{l}\text { Penaloza 2012, } \\
\text { US cohort }^{1642}\end{array}$ & PE & $7940(33)$ & 49 & 5.1 & $\begin{array}{l}\text { Hospital; outpatients } \\
\text { presenting in emergency } \\
\text { department or outpatient } \\
\text { clinics }\end{array}$ & $\begin{array}{l}\text { ((a) D-dimer <500 } \mu \mathrm{g} / \mathrm{L} \text {; or (b) normal } \\
\text { VQ scan; or (c) non-diagnostic VQ } \\
\text { scan and negative CUS and/or } \\
\text { negative D-dimer (d) negative } \\
\text { multidetector CT angiography) and } \\
\text { ( } 45 \text { days follow-up) }\end{array}$ & $\begin{array}{l}\text { ELFA or } \\
\text { quantitative latex } \\
\text { agglutination } \\
\text { assay }\end{array}$ & $\begin{array}{l}\text { Revised } \\
\text { Geneva } \\
\text { score }^{40}(\leq 10)\end{array}$ \\
\hline $\begin{array}{l}\text { Douma } 2010 \\
\text { validation set } 1^{6} \\
\text { 35 }\end{array}$ & PE & $3306(43)$ & $53(18)$ & 20 & $\begin{array}{l}\text { Hospital: inpatients and } \\
\text { outpatients }\end{array}$ & $\begin{array}{l}\text { ((a) Unlikely clinical probability and } \\
\text { D-dimer } \leq 500 \mu \mathrm{g} / \mathrm{L} \text {; or (b) negative } \\
\text { HCT) and ( } 3 \text { month event free } \\
\text { follow-up) }\end{array}$ & $\begin{array}{l}\text { ELFA or } \\
\text { quantitative latex } \\
\text { agglutination } \\
\text { assay }\end{array}$ & Wells $^{54}(\leq 4)$ \\
\hline Van Es $2012^{1755}$ & $\mathrm{PE}$ & $456(46)$ & 65 & 27 & $\begin{array}{l}\text { Hospital: inpatients and } \\
\text { outpatients }\end{array}$ & $\begin{array}{l}\text { ((a) Unlikely clinical probability and } \\
\text { D-dimer } \leq 500 \mu \mathrm{g} / \mathrm{L} \text {; or (b) negative } \\
\text { HCT) and ( } 3 \text { month event free } \\
\text { follow-up) }\end{array}$ & $\begin{array}{l}\text { ELFA or } \\
\text { quantitative latex } \\
\text { agglutination } \\
\text { assays }\end{array}$ & Wells $^{54}(\leq 4)$ \\
\hline $\begin{array}{l}\text { Schouten } \\
2012 \ddagger^{1856}\end{array}$ & DVT & $1374(27)$ & $59(17)$ & 20 & Primary care patients & Normal first and repeated CUS & $\begin{array}{l}\text { ELFA or } \\
\text { quantitative latex } \\
\text { agglutination } \\
\text { assay }\end{array}$ & Wells $^{9}(\leq 1)$ \\
\hline
\end{tabular}

Douma 2012, DVT $812(36) \quad 59(17) \quad 39 \quad$ Hospital; outpatients $\quad$ ((a) Non-high CDR and D-dimer $<500$ Quantitative latex Wells ${ }^{9}$ ( $\left.\leq 2\right)$ cohort $1^{719} \quad$ presenting in emergency $\mu \mathrm{g} / \mathrm{L}$; or (b) negative results from first agglutination department or outpatient CUS and D-dimer $<500 \mu \mathrm{g} / \mathrm{L}$; or (c) assay clinics normal results from repeated CUS) and (3 month event free follow-up)

\begin{tabular}{|c|c|c|c|c|c|c|c|c|}
\hline $\begin{array}{l}\text { Douma 2012, } \\
\text { cohort } 2^{1931}\end{array}$ & DVT & $474(38)$ & $61(19)$ & 23 & $\begin{array}{l}\text { Hospital; outpatients } \\
\text { presenting in emergency } \\
\text { department or outpatient } \\
\text { clinics }\end{array}$ & $\begin{array}{l}\text { ((a) D-dimer }<500 \mu \mathrm{g} / \mathrm{L} \text {; or (b) normal } \\
\text { CUS in combination with a non-high } \\
\text { clinical probability; or }(\mathrm{c}) \text { normal } \\
\text { phlebography) and ( } 3 \text { month event } \\
\text { free follow-up) }\end{array}$ & ELFA & $\begin{array}{l}\text { Clinical } \\
\text { probability } \\
\text { estimated by } \\
\text { treating } \\
\text { doctor }^{31} \\
(<80 \%)\end{array}$ \\
\hline $\begin{array}{l}\text { Douma 2012, } \\
\text { cohort } 3^{1932}\end{array}$ & DVT & $359(41)$ & $66(17)$ & 23 & $\begin{array}{l}\text { Hospital; outpatients } \\
\text { presenting in emergency } \\
\text { department or outpatient } \\
\text { clinics }\end{array}$ & $\begin{array}{l}\text { ((a) Low CDR and D-dimer }<500 \mu \mathrm{g} / \mathrm{L} \\
\text { and } 3 \text { month event free follow-up; or } \\
\text { (b) normal CUS or impedance } \\
\text { plethysmography. Patients with } \\
\text { intermediate CDR and D-dimer }<500 \\
\mu \mathrm{g} / \mathrm{L} \text { imaged at treating doctor's }\end{array}$ & $\begin{array}{l}\text { Quantitative latex } \\
\text { agglutination } \\
\text { assay }\end{array}$ & Wells $^{9}(\leq 2)$ \\
\hline
\end{tabular}


Table 1 (continued)

\begin{tabular}{|c|c|c|c|c|c|c|c|c|}
\hline Reference* & $\begin{array}{l}\text { PE or } \\
\text { DVT }\end{array}$ & $\begin{array}{c}\text { No of } \\
\text { patients } \\
\text { (\% male) }\end{array}$ & $\begin{array}{c}\text { Mean } \\
\text { age (SD) }\end{array}$ & $\begin{array}{c}\text { Prevalence } \\
\text { of VTE (\%) }\end{array}$ & Setting & Reference test to rule out VTE & D-dimer assayt & $\begin{array}{c}\text { CDR used } \\
\text { (cut-off) }\end{array}$ \\
\hline & & & & & & $\begin{array}{l}\text { discretion) and ( } 3 \text { month event free } \\
\text { follow-up) }\end{array}$ & & \\
\hline $\begin{array}{l}\text { Douma } 2012 \\
\text { cohort } 4^{1933}\end{array}$ & DVT & $556(38)$ & $65(16)$ & 10 & $\begin{array}{l}\text { Hospital; outpatients } \\
\text { presenting in emergency } \\
\text { department or outpatient } \\
\text { clinics }\end{array}$ & $\begin{array}{l}\text { ((a) Non-high CDR and normal } \\
\text { D-dimer test and } 3 \text { month event free } \\
\text { follow-up; or (b) normal repeated } \\
\text { CUS) and ( } 3 \text { month event free } \\
\text { follow-up) }\end{array}$ & $\begin{array}{l}\text { Quantitative latex } \\
\text { agglutination } \\
\text { assay }\end{array}$ & Wells $^{9}(\leq 2)$ \\
\hline $\begin{array}{l}\text { Douma 2012, } \\
\text { cohort } 5^{19} \text { (Tan } \\
\text { et al, } \\
\text { unpublished) }\end{array}$ & DVT & $617(52)$ & $58(18)$ & 37 & $\begin{array}{l}\text { Hospital; outpatients } \\
\text { presenting in emergency } \\
\text { department or outpatient } \\
\text { clinics }\end{array}$ & $\begin{array}{l}\text { (a) Unlikely CDR and D-dimer }<500 \\
\mu \mathrm{g} / \mathrm{L} \text {; or (b) negative results from (first) } \\
\text { leg venous CUS in combination with } \\
\text { normal D-dimer }<500 \mu \mathrm{g} / \mathrm{L} \text {; or (c) } \\
\text { normal repeated CUS }\end{array}$ & $\begin{array}{l}\text { Quantitative latex } \\
\text { agglutination } \\
\text { assay }\end{array}$ & Wells $^{9}(\leq 1)$ \\
\hline
\end{tabular}

$\mathrm{PE}=$ pulmonary embolism; DVT=deep vein thrombosis; VTE=venous thromboembolism; CDR=clinical decision rule; ELISA=enzyme linked immunosorbent assay; $E L F A=e n z y m e$ linked fluorescent assay; CUS=compression ultrasonography of leg (if repeated; 6-8 days after initial presentation); HRCT=helical computed tomography of chest; $\mathrm{VQ}=$ ventilation perfusion.

*Second reference refers to primary studies describing cohort.

†Classified according to Heim et al and Di Nisio et al. ${ }^{248}$

$\ddagger$ Study also presented data for cut-off value of $750 \mathrm{ug} / \mathrm{L}$ in patients aged $>60$ years. ${ }^{18}$ These data were not included in this meta-analysis. 
Table 2| Pooled estimates of diagnostic accuracy of D-dimer testing in older patients with suspected venous thromboembolism and non-high clinical probability per age category and cut-off value in 13 study cohorts

\begin{tabular}{|c|c|c|c|c|c|c|c|c|}
\hline \multirow[b]{2}{*}{$\begin{array}{l}\text { Age } \\
\text { (years) }\end{array}$} & \multirow[b]{2}{*}{$\begin{array}{l}\text { No of } \\
\text { patients }\end{array}$} & \multirow{2}{*}{$\begin{array}{c}\text { Median (range) } \\
\text { prevalence } \\
\text { within studies } \\
(\%)\end{array}$} & \multicolumn{3}{|c|}{ Pooled sensitivity $(95 \% \mathrm{Cl})$} & \multicolumn{3}{|c|}{ Pooled specificity $(95 \% \mathrm{Cl})$} \\
\hline & & & $\begin{array}{l}\text { Conventional } \\
\text { cut-off (\%) }\end{array}$ & $\begin{array}{l}\text { Age adjusted } \\
\text { cut-off }(\%)\end{array}$ & $P$ value & $\begin{array}{l}\text { Conventional } \\
\text { cut-off (\%) }\end{array}$ & $\begin{array}{l}\text { Age adjusted } \\
\text { cut-off }(\%)\end{array}$ & $P$ value \\
\hline$\leq 50$ & $5528^{*}$ & $12.3(3.09-28.6)$ & 97.6 (95.0 to 98.9$)$ & NA† & NA† & $66.8(61.3$ to 72.0$)$ & NAt & NA† \\
\hline $51-60$ & $2043^{*}$ & $13.4(5.00-33.3)$ & $100.0(\mathrm{NA})$ & 99.4 (97.3 to 99.9 ) & 0.97 & $57.6(51.4$ to 63.6$)$ & 62.3 (56.2 to 68.0$)$ & 0.005 \\
\hline $61-70$ & 1815 & $15.6(6.58-26.2)$ & 99.0 (96.6 to 99.7$)$ & 97.3 (93.8 to 98.8 ) & 0.14 & 39.4 (33.5 to 45.6$)$ & 49.5 (43.2 to 55.8$)$ & $<0.001$ \\
\hline $71-80$ & 1842 & $21.5(6.78-34.5)$ & 98.7 (96.5 to 99.5$)$ & 97.3 (94.3 to 98.8 ) & 0.20 & 24.5 (20.0 to 29.7$)$ & 44.2 (38.0 to 50.5$)$ & $<0.001$ \\
\hline$>80$ & 1269 & $15.2(5.88-26.9)$ & 99.6 (96.9 to 99.9$)$ & $97.0(92.9$ to 98.8$)$ & 0.06 & $14.7(11.3$ to 18.6$)$ & 35.2 (29.4 to 41.5$)$ & $<0.001$ \\
\hline
\end{tabular}

*Additional data of cohort 5 of Douma 2012 study (Tan et al, unpublished), were not provided for these age categories ( 89 patients aged $<50$ years and 44 patients aged 51-60 years).

†Age adjusted cut-off value (age $\times 50 \mu \mathrm{g} / \mathrm{L}$ ) does not apply (NA) to patients aged $\leq 50$ years. 
Table 3| Overall and covariate analysis for D-dimer testing stratified by use of conventional and age adjusted cut-off levels in patients with a non-high clinical probability of venous thromboembolism (all age categories except $<50$ years)

\begin{tabular}{|c|c|c|c|c|c|}
\hline \multirow[b]{2}{*}{ Analyses } & \multirow{2}{*}{$\begin{array}{l}\text { No of } \\
\text { cohorts }\end{array}$} & \multicolumn{2}{|c|}{ Sensitivity (95\% Cl) } & \multicolumn{2}{|c|}{ Specificity (95\% Cl) } \\
\hline & & Conventional cut-off (\%) & Age adjusted cut-off (\%) & Conventional cut-off (\%) & Age adjusted cut-off (\%) \\
\hline $\begin{array}{l}\text { Overall analyses: } \\
\text { age-categories }>50 \text { years }\end{array}$ & 13 & 99.3 (98.4 to 99.7 ) & 97.8 (95.9 to 98.9 ) & 36.1 (30.8 to 41.7 ) & 48.8 (42.9 to 54.7$)$ \\
\hline \multicolumn{6}{|l|}{$\begin{array}{l}\text { Prevalence in cohort } \\
\text { (overall): }\end{array}$} \\
\hline$<23 \%$ & 7 & 99.4 (98.2 to 99.8$)$ & 97.9 (95.3 to 99.1$)$ & 37.5 (30.4 to 45.2$)$ & 49.9 (42.0 to 57.7$)$ \\
\hline$>23 \%$ & 6 & 99.1 (97.0 to 99.7 ) & 97.7 (94.2 to 99.1$)$ & 34.2 (26.7 to 42.5$)$ & 47.8 (39.1 to 56.5 ) \\
\hline$P$ value & - & 0.64 & 0.89 & 0.56 & 0.73 \\
\hline \multicolumn{6}{|l|}{ D-dimer assay: } \\
\hline Only ELFA & 3 & $100(\mathrm{NA})$ & 99.6 (98.2 to 99.9$)$ & 28.69 (20.6 to 38.5 ) & 40.8 (30.8 to 51.7$)$ \\
\hline $\begin{array}{l}\text { Quantitative latex assay } \\
\text { (and ELFA)† }\end{array}$ & 10 & 98.7 (97.5 to 99.3$)$ & 96.4 (94.6 to 97.6 ) & 35.6 (32.9 to 42.5 ) & 51.3 (45.2 to 57.4$)$ \\
\hline$P$ value & - & 0.97 & 0.005 & 0.08 & 0.10 \\
\hline \multicolumn{6}{|l|}{ Clinical suspicion: } \\
\hline Pulmonary embolism & 7 & 99.2 (97.9 to 99.7 ) & 97.5 (94.7 to 98.8 ) & $34.0(27.7$ to 40.9$)$ & 45.7 (38.5 to 53.1$)$ \\
\hline Deep vein thrombosis & 6 & 99.8 (97.8 to 99.97$)$ & 99.3 (96.6 to 99.8 ) & 36.0 (34.0 to 38.0$)$ & 48.0 (45.8 to 50.2$)$ \\
\hline$P$ value & - & 0.31 & 0.15 & 0.58 & 0.55 \\
\hline
\end{tabular}

ELFA=enzyme linked fluorescent assay; NA=not applicable.

${ }^{*}$ Covariate analysis for setting was not possible as only one study was performed in primary care.

†This stratum contains studies wherein quantitative latex agglutination assays were used, or latex agglutination assays indifferently with ELFA assays. 
Table 4| Classification table for 1000 hypothetical patients based on median prevalence of venous thromboembolism (VTE) in each age subgroup* and on pooled estimates of sensitivity and specificity

\begin{tabular}{|c|c|c|c|c|c|c|c|c|c|c|c|c|c|c|c|}
\hline \multirow{3}{*}{$\begin{array}{l}\text { Variables } \\
\text { Conventional cut-off } \\
\text { value }\end{array}$} & \multicolumn{15}{|c|}{ Age (years) } \\
\hline & \multicolumn{3}{|c|}{$\leq 50$} & \multicolumn{3}{|c|}{$51-60$} & \multicolumn{3}{|c|}{$61-70$} & \multicolumn{3}{|c|}{$71-80$} & \multicolumn{3}{|c|}{$>80$} \\
\hline & VTE+ & VTE- & Total & VTE+ & VTE- & Total & VTE+ & VTE- & Total & VTE+ & VTE- & Total & VTE+ & VTE- & Total \\
\hline D-dimer high & 120 & 291 & 411 & 134 & 367 & 501 & 154 & 512 & 666 & 212 & 593 & 805 & 151 & 724 & 876 \\
\hline D-dimer low & 3 & 586 & 589 & 0 & 499 & 499 & 2 & 332 & 334 & 3 & 192 & 195 & 1 & 124 & 124 \\
\hline Total & 123 & 877 & 1000 & 134 & 866 & 1000 & 156 & 844 & 1000 & 215 & 785 & 1000 & 152 & 848 & 1000 \\
\hline Sensitivity/specificity & 97.6 & 66.8 & - & 100.0 & 57.6 & - & 99.0 & 39.4 & - & 98.7 & 24.5 & - & 99.6 & 14.6 & - \\
\hline $\begin{array}{l}\text { Age adjusted cut-off } \\
\text { value }\end{array}$ & - & - & - & VTE+ & VTE- & Total & VTE+ & VTE- & Total & VTE+ & VTE- & Total & VTE+ & VTE- & Total \\
\hline D-dimer high & - & - & - & 133 & 327 & 460 & 152 & 427 & 578 & 209 & 438 & 647 & 147 & 550 & 697 \\
\hline D-dimer low & - & - & - & 1 & 539 & 540 & 4 & 417 & 422 & 6 & 347 & 353 & 5 & 298 & 303 \\
\hline Total & - & - & - & 134 & 866 & 1000 & 156 & 844 & 1000 & 215 & 785 & 1000 & 152 & 848 & 1000 \\
\hline Sensitivity/specificity & - & - & - & 99.4 & 62.3 & - & 97.3 & 49.5 & - & 97.3 & 44.2 & - & 97.0 & 35.2 & - \\
\hline $\begin{array}{l}\text { No of avoided } \\
\text { unnecessary imaging } \\
\text { examinations }\end{array}$ & - & - & - & - & 40 & - & - & 85 & - & - & 155 & - & - & 175 & - \\
\hline $\begin{array}{l}\text { Additional No of } \\
\text { cases missed }\end{array}$ & - & - & - & 1 & - & - & 2 & - & - & 3 & - & - & 4 & - & - \\
\hline
\end{tabular}

${ }^{*} 12.3 \%$ in patients aged $\leq 50,13.4 \%$ in patients aged $51-60,15.6 \%$ in patients aged $61-70,21.5 \%$ in patients aged $71-80$, and $15.2 \%$ in patients aged $>80$ years. 


\section{Figures}

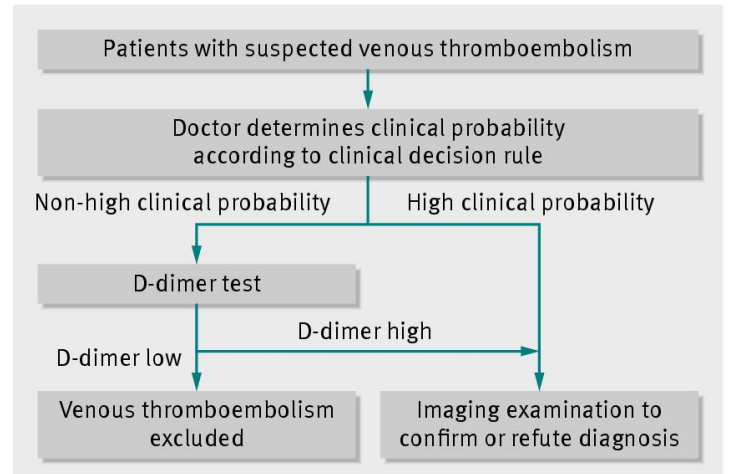

Fig 1 Diagnostic investigations in patients with suspected venous thrombembolism. Adapted from Wells $2007,{ }^{9}$ Le Gal et al $2006,{ }^{40}$ and Wells et al $2001^{57}$

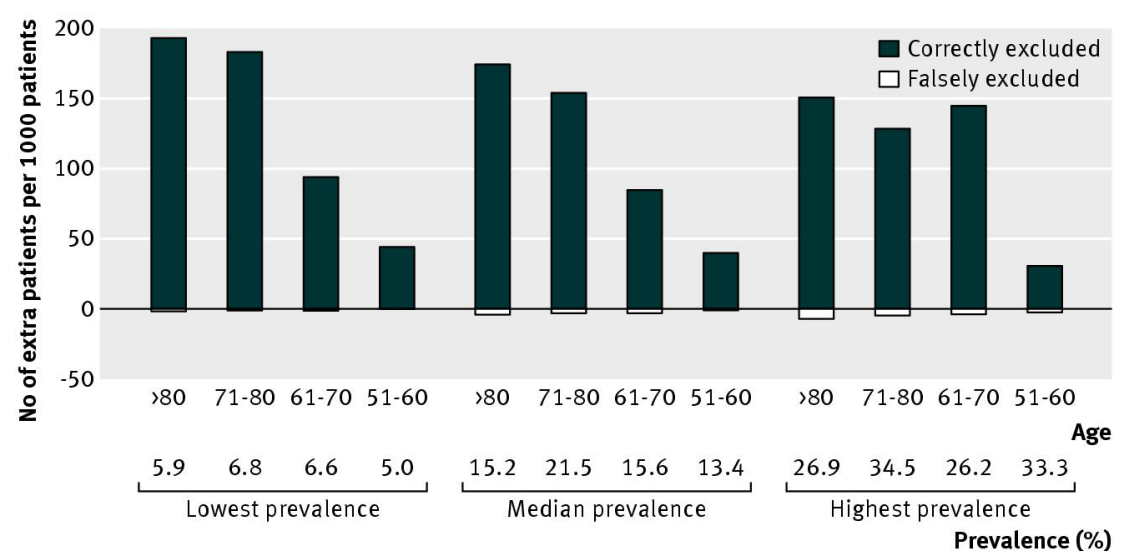

Fig 2 Number of extra patients per 1000 patients with non-high clinical probability in whom venous thromboembolism would be correctly or falsely excluded by application of age adjusted D-dimer cut-off values instead of conventional cut-off values 